\title{
Surgeons' Perception to Needle Stick Injuries and Transmission of Blood Borne Viral Infections
}

\author{
Pravin K Nair ${ }^{1 *}$ and Ekta Chourasia ${ }^{2}$ \\ ${ }^{1}$ Consultant Microbiologist \& Head Infection prevention, Holy Spirit Hospital, India \\ ${ }^{2}$ Consultant Microbiologist, Singapore
}

*Corresponding author: Pravin K Nair, Consultant Microbiologist \& Head Infection prevention Holy Spirit Hospital, Mumbai, Maharashtra, India

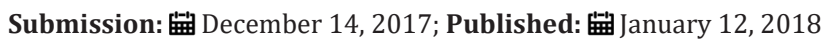

\begin{abstract}
Objective: Needle stick injuries (NSIs) are common amongst surgeons with a potential risk of transmission of blood-borne pathogens particularly HBV, HCV and HIV. The aim of this study was to assess the surgeons' perception to the transmission of blood borne viral infections, their experience in dealing with such an occupational risk and identify why NSI remains unreported in majority of cases.

Methods: A questionnaire based survey was conducted among 31 surgeons of different specialties with different levels of experience.

Results: Nineteen (61.2\%) surgeons had a history of exposure/ NSI in the past and none of them ever reported the incidence to concerned authority. The process is felt very time consuming and too complex compared to the perceived low risk of transmission.
\end{abstract}

Conclusion: Surgeons are at a higher risk of exposure to infection. There should be strategies to increase reporting and promotion of awareness to universal safety precautions. And hence a felt need for efficient and user-friendly reporting system.

Keywords: Needle stick injuries; Surgeons; Perception; Blood borne viral infections; Survey

\section{Introduction}

Needle stick injuries (NSI) are commonly seen in health care workers and those into surgical practice are at a higher risk of sustaining such injuries. As per WHO Report of 2002, of the 35 million health-care workers, 2 million experience percutaneous exposure to infectious diseases every year. It further adds that $37.6 \%$ of Hepatitis B, $39 \%$ of Hepatitis C and $4.4 \%$ of HIV/AIDS in Health-Care Workers (HCWs) around the world are due to NSI. There are more than 20 blood-borne pathogens which can be transmitted by contaminated needles or sharps, but those which are of utmost significance to HCWs include HBV, HCV and HIV [1].

The risk of needle stick injuries to health care workers is higher in developing countries as compared to developed and in most cases, it remains unreported or under-reported. There is a scarcity of data from India and hence difficulty in estimating the annual incidence [2]. However, studies have shown that the average transmission rates for HBV, HCV and HIV are 33.3\%, 3.3\% and 0.3 $\&$ respectively [3].

\section{Materials and Methods}

A questionnaire based survey was conducted by the department of Microbiology at a tertiary care hospital in Mumbai. The proforma was completed by 31 surgeons of different specialties belonging to different age groups with varying years of experience. Any sex wise differentiation among surgeons was not considered. The survey aimed at three aspects:

a) To assess the surgeons' perception to the transmission of blood borne infections primarily HBV, HCV and HIV

b) Their experience in dealing with such an occupational risk

c) To identify why NSI remains unreported

\section{Results}

Thirty-one surgeons from different surgical specialties participated in the survey, of which twelve (38.7\%) chose not to disclose their departments. Remaining participating surgeons were from the departments of orthopedics $(n=5)$, ENT $(n=3)$, general surgery $(n=6)$ and gynecology $(n=5)$. A total of 19 surgeons $(61.2 \%)$ had a history of occupational exposure to NSI. Sixteen of $31(51.6 \%)$ surgeons were under 35 years of age with 11surgeons (35.4\%) having just one to five years of clinical experience. Though these surgeons were aware of the occupational risk of transmission of blood borne viral pathogens following NSI, only six (19.35\%) felt that they were at a high risk of infection whereas twenty (64.5\%) surgeons believed were at moderate risk. 
There were 19surgeons with a history of needle-stick injuries in the past but none of them ever reported the incidence of NSI. They mentioned that excessive paperwork is the main reason for not reporting the incidence and a few were also of the opinion that it's pointless to report. Of all the surgeons, twenty-one $(67.7 \%)$ were aware of the existence of post-exposure protocols but only ten $(32.3 \%)$ were familiar with the standard post-exposure reporting procedure and appropriate use of post-exposure prophylaxis (PEP). Twenty-three (74.1\%) of these surgeons were aware of their immunization status and reported having been vaccinated against HBV.

\section{Discussion}

Needle-stick injuries are common amongst surgical practice. The surgeons do not report these injuries routinely and therefore; the injury rates remain extremely under-estimated. In this study, we have attempted to find out the barriers to under-reporting. Majority of the surgeons attributed this to excessive paperwork, too time consuming a process of reporting, and that the risk of transmission of viruses is low since they have received vaccination against HBV in the past However, the risk of viral transmission for HCV and HIV is quite significant with an average seroconversion rate of $3 \%$ for HCV and $0.3 \%$ for HIV [4- 6]. Wallis et al have documented in their study that the orthopedic consultants found this reporting system far too complex to report incidences of percutaneous exposure [7]. This was a small, retrospective study confined to only one tertiary care centre and we could not rule out some degree of recall bias to the study. However, our results are quite comparable to studies conducted by Kennedy et al [8] in UK in which $81 \%$ of surgeons had suffered at least one NSI. Another study by Makary et al [9] showed that $51 \%$ of NSIs remain unreported among residents and trainees.

Around $74.1 \%$ had received vaccination against hepatitis B as compared to $57.1 \%$ reported by Randive et al [10] and $60 \%$ by Gurubacharya et al [11]. We postulate that the surgeons have a sense of security arising from HBV vaccination. They would make an initial risk assessment and if they deem patient to be low risk, it's quite unlikely to report incidences of NSI.

Creative Commons Attribution 4.0

International License

For possible submission use the below is the URL

\section{Conclusion}

In conclusion, we perceive that the surgical cohort is at a higher risk than the need be. So there should be strategies to overcome the differences between incident and reporting rate. The reporting system can be made more user-friendly along with less paper work. They should be encouraged to report each incidence of NSI for the correct management of potential transmission, no matter how rare an event of exposure is. Our focus should be to remain vigilant and be pro-active in case of such an event. This should be combined with a regular review of preventive guidelines and promotion of awareness to universal safety precautions.

\section{References}

1. The world health report 2002 - Reducing Risks, Promoting Healthy Life.

2. Rodrigues (2010) Needle stick injuries and the health care worker -the time to act is now -a commentary Indian J Med Res 131(3): 384-386.

3. Muralidhar V, Muralidhar S (2006) Safety and risk management. In: Muralidhar V, Muralidhar S (Eds). Hospital acquired infections -power strategies for clinical practice Viva Books Pvt Ltd, India. P. 110.

4. Jefferies D (1995) Surgery and blood borne viruses. Public Health Lab Serv Microbiol Dig 12:150-154.

5. Deisenhammer S, Radon K, Nowak D, Reichert J (2006) Needle stick injuries during medical training. J Hosp Infect 63(3):263-267.

6. Tabak N, Shiabana AM, Shasha S (2006) The health beliefs of hospital staff and the reporting of needlestick injury. J ClinNurs 15(10): 12281239.

7. Wallis GC, Kim WY, Chaudhary BR, Henderson JJ (2007) Perceptions of orthopaedic surgeons regarding hepatitis $C$ viral transmission: a questionnaire survey. Ann R Coll Surg Engl 89(3): 276-80.

8. Kennedy R, Kelly S, Gonsalves S, McCann PA (2009) Barriers to the reporting and management of needle stick injuries among surgeons. Ir ] Med Sci 178(3): 297 -299.

9. Makary M, Al-Attar A, Holzmueller CG, sexton Jb, syin D et al.( 2007) Needle stick injuries among surgeons in training. N Eng J Med 356(26): 2693-2699.

10. Randive M, Ramchandran A, Turbadkar D, Baveja S (2017) An audit of sharp injuries at a tertiary care hospital in Mumbai, India. Int J CurrMicrobiol App Sci 6(1): 201-206.

11. Gurubacharya DL, Mathura KC, Karki DB (2003) Knowledge, attitude and practices among health care workers on needle-stick injuries. Kathmandu Univ Med J 1(2): 91-94.

\section{Your subsequent submission with Crimson Publishers will attain the below benefits}

- High-level peer review and editorial services

- Freely accessible online immediately upon publication

- Authors retain the copyright to their work

- Licensing it under a Creative Commons license

- Visibility through different online platforms

- Global attainment for your research

- Article availability in different formats (Pdf, E-pub, Full Text)

- Endless customer service

- Reasonable Membership services

- Reprints availability upon request

- One step article tracking system 